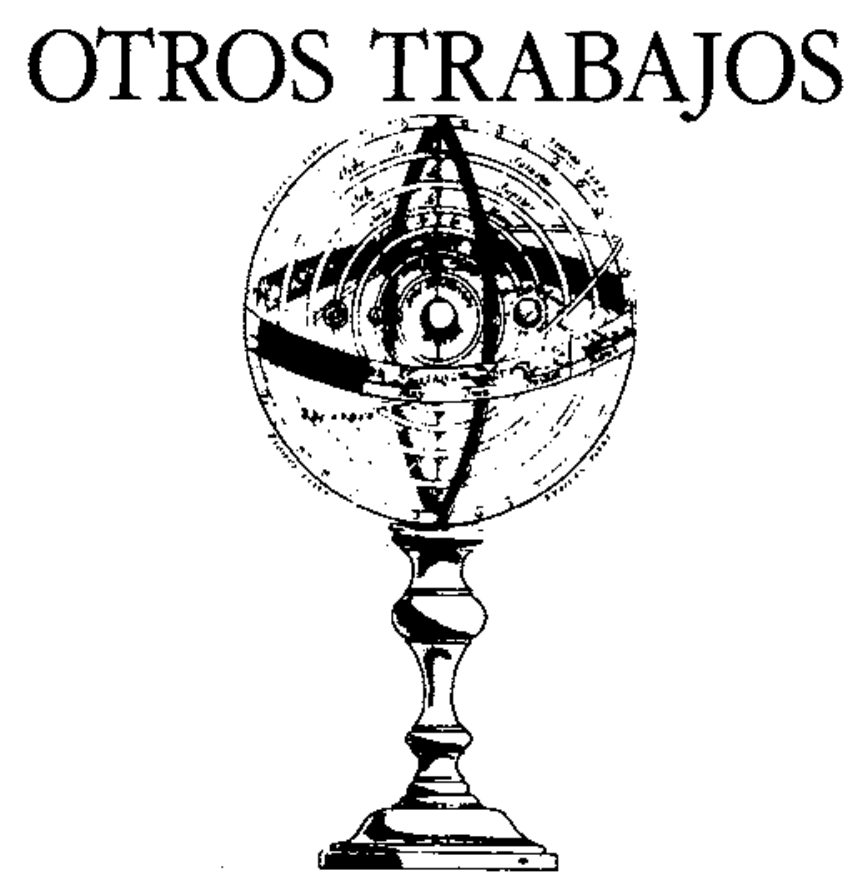

\title{
LOS MUSEOS DE LA CIENCIA Y LA TÉCNICA, ENTRE LAS MUSAS Y LA MODERNIDAD
}

\section{VIVES, J.}

Responsable de actividades y exposiciones del Museu de la Ciència de la Fundací́ «la Caixa». Barcelona.

\section{SUMMARY}

After a short miscellany about the evolution of Science Museums, a debate on the question "Must Science Museurns be used for motivation or for learning?", is opened.

\section{UNA EXPERIENCIA IMPACTANTE}

Debo reconocer que el ya lejano día en que ví las primeras salas en proceso de acabado del actual Museu de la Ciència descubrí algo que para mí era desconocido. No había visitado, antes de ese momento, ningún gran museo de la ciencia como tampoco ningún museo técnico y, por tanto, no había experimentado ni la fascinación que determinadas máquinas pueden ejercer ni la sorpresa que los dispositivos interactivos generan cuando no se los conoce. El impacto sobre el visitante puede ser realmente fuerte. 
Si los museos (los templos de las musas) nacieron en general con un espíritu de protección del pasado, los museos científicos y técricos más antiguos estuvieron más vinculados al interés de mostrar los avances científicos. De hecho, las Exposiciones Internacionales aparecieron con ese objetivo y jugaron, y han continuado jugando hasta tiempos recientes, un papel muy destacado en el nacimiento de museos científico-técnicos. Así, el Science Museum nace en Londres en 1865, nueve años más tarde de la Exposición Internacional de la misma ciudad, como consecuencia del gran éxito de público que tuvo la exhibición de las innovaciones tecnológicas durante la Exposición.

Este nacimiento está, pues, vinculado a una voluntad de extender tecnología, y a una voluntad que podríamos llamar divulgativa (en terminología «moderna»). Y el elemento impactante es ya un elemento importante en este nacimiento, puesto que las Exposiciones han jugado siempre con la pretensión de crear un impacto en la sociedad de la época y en los individuos.

Pero quizá hay que esperar al nacimiento del Deutsches Museum (1903, en Munich) para hablar de una voluntad de extender «conocimiento» y no estrictamente tecnología (aunque ésta es un conocimiento práctico, por lo menos). Este museo incorpora, paralelamente a la presentación de la tecnología, dos elementos: a) uno histórico-cultural, constituido por elementos de contextualización histórica que sitúen la técnica en el marco de la historia en general y, más en particular, que subrayen los elementos culturales vinculados a la creación y utilización de ciencia y tecnología; y b) uno «científico», constituido por montajes paralelos que muestren los principios de funcionamiento de las máquinas y de la tecnología. Encontramos, pues, aquí una voluntad «didáctica» aplicada a Ia concepción de los espacios permanentes de los museos técnicos, y que hace trascender la noción de colección de piezas históricas como fundamento único de un museo.

\section{DE LA EXPLICACIÓN DE LA TECNOLOGÍA AL PRINCIPIO CIENTIFICO}

Pero el próximo paso estaba todavía por llegar, y era la continuación lógica de la innovación introducida por el Deutsches: convertir los dispositivos diseñados para explicar los principios científicos en elementos autónomos e independientes de las piezas técnicas. Consistía en Ilevar a sus últimas consecuencias lógicas la idea de sustituir el «mostrar» objetos técnicos por el de «demostrar» cómo funciona la naturaleza y cómo podemos utilizar esas leyes científicas.

Este paso fue introducido por el Palais de la Découverte en París en 1937, aunque esta concepción no se desarollaría en Europa hasta que el Exploratorium de San Francisco y el Ontario Science Center en Toronto desarrolIarian esta filosofía y se convertirían en los padres del movimiento de science centers en USA, que más tarde volvería a Europa como una influencia de ultramar y no como el desarrollo de unos conceptos que en sus orígenes históricos habían sido genuinamente europeos.

Existe una cierta continuidad histórica entre estos distintos modelos que todavía pueden verse en la actualidad en forma más o menos modificada y, a menudo, de forma entremezclada como fruto de la evolución que cada museo ha tenido. No es fácil generalizar sobre museos en la medida que cada museo tiene una muy particular personalidad, fruto de su entorno histórico y cultural, del tipo de material de que dispone, tipo de edificio, etc. En cualquier caso, los museos científicos y técnicos constituyen unos recursos educativos y didácticos que pueden ser usados por todo tipo de ciudadanos y, muy en particular, por las instituciones escolares. $Y$, como hemos visto, el elemento didáctico es un elemento que ha sido muy importante en la propia historia de los museos técnicos y científicos.

\section{ESPACIOS PERMANENTES Y ESPACIOS TEMPORALES}

La mayoría de los museos, grandes o pequeños, concede una creciente importancia a la disponibilidad de unos espacios dedicados a montajes temporales, es decir, a exposiciones temporales. Existen distintos motivos para esta tendencia. Quizá el más importante pertenezca al dominio del marketing. Los espacios temporales juegan un papel fundamental en recordar al visitante habitual que existen novedades, en hacerle repetir visita, o en atraer a un visitante no habitual pero al que el tema de la exposición le resulta atractivo y así consigue hacerle entrar en el museo. Existen casos donde la estrategia de presentación y promoción de una exposición consigue una imagen pública de producto cultural imprescindible, muy por encima de la imagen de importancia que el mismo material tenía antes de constituirlo como exposición. Conseguir mantener la cifra de visitantes de un nuevo museo, tras el período inicial en que el impacto de la inauguración constituye un estímulo suficiente para que un gran número de gente lo visite, resulta el gran reto para cualquier equipo de direccion.

Existen también motivos de otro tipo, digamos más de contenido por oposición a los motivos de gestión. Por una parte, los museos con colecciones pueden tener parte de su material guardado (al margen de sus espacios permanentes) y presentarlo al público en exposiciones temporales. Por otra, este tipo de exposiciones puede tener mucha más libertad en el tratamiento de temas y en el estilo museográfico, y así superar las limitaciones de los espacios permanentes.

Las exposiciones temporales suelen plantear posibilidades muy variadas para las escuelas. Si los espacios permanentes permiten una planificación estable de visita y aprovechamiento, los espacios temporales exigen una planificación más a corto plazo. Pero quizá el mayor reto que pueden presentar deriva de su relación, muy variable, con los programas escolares. Muchas veces el tratamiento que las exposiciones hacen de un tema es mucho 
más libre, con lo que guardan una relación más problemática con los programas y estructuras escolares.

\section{DEL AUTOSERVICIOALA DEMOSTRACIÓN CON MONITOR}

Si los espacios permanentes constituyen un autoservicio para el visitante, ya que puede verlos completamente a su aire, en el orden que quiera, en el tiempo que su propio horario le permita y sin que nadie se lo explique, los museos también disponen en ocasiones de unos espacios específicos que funcionan con personal propio y con horario de funcionamiento. Ello incluye espacios tan caracterizados como los planetarios incluidos en el interior de museos; pero es de otro tipo de espacios de los que quiero aquí hablar. Ni los objetos técnicos estáticos ni los elementos interactivos habituales pueden, por razones de seguridad de los propios aparatos y de los usuarios, o por razones del consumo de materiales que comportarían, o por la complejidad que supondría, agotar muchos campos científicos. La química, por ejemplo, plantea graves problemas para los dispositivos interactivos por razón del consumo de reactivos que supone un dispositivo que pueda accionar siempre que quiera un visitante. La electricidad, elemento técnico clave en la vida moderna, tiene la gran dificultad museística que no es «visible» directamente y debe habitualmente «manifestarse» mediante sus efectos externos. Una solución posible es individualizar unos espacios donde un monitor del museo realice un conjunto de experimentos sobre un tema siguiendo un guión y un horario predeterminado. Algunos museos, como el mismo Palais de la Découverte, conceden una importancia considerable a este tipo de programas, dedicando un espacio considerable a un número apreciable de demostraciones distintas. Otros museos incluyen sólo alguna demostración de temas muy espectaculares (como demostraciones de electricidad con alta tensión).

\section{Los talleres escolares}

Otra posibilidad parecida a la anterior es realizar programas de demostraciones de forma exclusiva para escuelas. La diferencia está en el tipo de guión y en la duración de las sesiones. Las sesiones de demostración para un público en general tienen una duración relativamente limitada y un guión a veces muy poco sistemático. Su finalidad fundamental no es académica. Las sesiones para escuelas suelen ser más largas y sistemáticas. A menudo, los mismos espacios ofrecen sesiones distintas para cada tipo de público.

Estas sesiones para escuelas cubren un espacio parecido al de las sesiones en el laboratorio escolar, pero utilizando aparatos que difícilmente formarán parte del equipamiento de los centros escolares. Por otra parte, estas sesiones pueden estar pensadas para alumnos de edades muy variadas, desde el período de parvulario hasta alumnos de COU. Algunos museos disponen de espacios permanentes para edades comprendidas entre los 3 y los 10 años (a veces en forma de dos espacios que cubren los períodos 3-6 y 7-10 años).

\section{OTRAS ACTIVIDADES: DE LA FERIA CIENTIFICA A LOS CONGRESOS}

Los inuseos pueden ser el espacio donde ocurran muchas otras cosas: actividades de todo tipo (cursos, conferencias, seminarios, congresos, proyecciones científicas, etc.).

De este variado conjunto podríamos destacar las que más directamente pueden ser utilizadas desde la escuela como un recurso educativo útil: por un lado, las denominadas ferias científicas (que no siempre se realizan en el marco de museos), y por otro las conferencias de divulgación. Las ferias pueden incluir actividades muy variadas, pero la presentación de proyectos científicos realizados en el marco de las escuelas o de otras organizaciones podj'ía ser el elemento más característico y diferenciador.

Las conferencias pueden constituir un recurso útil en el caso de alumnos de COU o universitarios. El contacto directo con cientificos en conferencias puede constituir una experiencia muy interesante para estudiantes no universitarios, y el profesor de ciencias puede utilizar la asistencia de formas muy variadas.

\section{¿MOTIVACIÓN O APRENDIZAJE?}

To be or not to be... recita Hamlet, y desde el público un desconcertado profesor, reciente visitante de un museo, balbucea: ¿motivación o aprendizaje? sumidoen el particular dilema que suele atenazar al profesional de la enseñanza que se plantea si el museo es ... una cosa o la otra para sus alumnos. Evidentemente, puede que no sea $\mathrm{A}$ ni $\mathrm{B}$, sino todo lo contrario; pero esta complicación que pugna por salir a flote queda rápidamente ahogada por las consideraciones en favor de A o de B. Probablemente la tendencia natural (es decir, la que la situación profesional y cotidiana condiciona y tiende a producir espontáneamente) es pensar que, al igual que en el marco estricto de las instituciones escolares, lo que hace (o quizás mejor lo que debe hacer) un alumno en un museo es aprender cosas, científicas en esta ocasión, ya que hablamos de este tipo de museos.

Teniendo en cuenta la amplia variedad de recursos edıcativos que los museos técnicos y científicos pueden ofrecer a las instituciones escolares y educativas, no es fácil de contestar al dilema que se plantea a nuestro atribulado profesor. Este es un tema que este artículo ha pretendido introducir, dandoun primer marco de referencia y abriéndolo a intervenciones posteriores. 